OPEN ACCESS

Edited by:

George Qian Li,

Western Sydney University,

Australia

Reviewed by:

Wenda Xue,

Nanjing University of Chinese Medicine, China Yanfang Zheng,

Fujian University of Traditional Chinese Medicine, China

*Correspondence:

Yuan-Wei Zhang

yuanwei.zhang@yale.edu

Specialty section:

This article was submitted to

Ethnopharmacology,

a section of the journal

Frontiers in Pharmacology

Received: 19 February 2020

Accepted: 16 April 2020

Published: 07 May 2020

Citation:

Li C, Huang J, Cheng $Y-C$ and Zhang Y-W (2020) Traditional Chinese Medicine in Depression Treatment:

From Molecules to Systems.

Front. Pharmacol. 11:586.

doi: 10.3389/fphar.2020.00586

\section{Traditional Chinese Medicine in Depression Treatment: From Molecules to Systems}

\author{
Chan $\mathrm{Li}^{1,2}$, Junying Huang ${ }^{1}$, Yung-Chi Cheng ${ }^{2}$ and Yuan-Wei Zhang ${ }^{1,2 *}$ \\ ${ }^{1}$ School of Life Sciences, Guangzhou University, Guangzhou, China, ${ }^{2}$ Department of Pharmacology, School of Medicine \\ Yale University, New Haven, CT, United States
}

Depression is a multigenetic or multifactorial syndrome. The central neuron system (CNS)orientated, single target, and conventional antidepressants are insufficient and far from ideal. Traditional Chinese Medicine (TCM) has historically been used to treat depression up till today, particularly in Asia. Its holistic, multidrug, multitarget nature fits well with the therapeutic idea of systems medicine in depression treatment. Over the past two decades, although efforts have been made to understand TCM herbal antidepressants at the molecular level, many fundamental questions regarding their mechanisms of action remain to be addressed at the systems level in order to better understand the complicated herbal formulations in depression treatment. In this Mini Review, we review and discuss the mechanisms of action of herbal antidepressants and their acting targets in the pathological systems in the brain, such as monoamine neurotransmissions, hypothalamic-pituitary-adrenal (HPA) axis, neurotropic factor brain-derived neurotrophic factor (BDNF) cascade, and glutamate transmission. Some herbal molecules, constituents, and formulas are highlighted as examples to discuss their mechanisms of action and future directions for comprehensive researches at the systems level. Furthermore, we discuss pharmacological approaches to integrate the mechanism of action from the molecular level into the systems level for understanding of systems pharmacology of TCM formulations. Integration of the studies at the molecular level into the systems level not only represents a trend in TCM study but also promotes our understanding of the system-wide mechanism of action of herbal antidepressant formulations.

Keywords: traditional Chinese medicine, depression treatment, mechanism of action, systems pharmacology, neuropharmacology

\section{INTRODUCTION}

Depression is a chronic, prevalent, and debilitating mental illness that influences $15-20 \%$ of the population over the globe (Hasin et al., 2018). According to a recent report by the World Health Organization, depression is the leading cause of disability and a major contributor to the general burden of illness (WHO, 2017). Therefore, development of effective antidepressants will provide enormous social, economic, and health benefits. 
Depression is not a unified syndrome, in which multiple underlying mechanisms exist. It is impossible to identify a specific factor that leads to or stops depression in all patients (Villas Boas et al., 2019). Hence, the better healing approach could be to seek the unique cause for each individual patient and then to apply a personalized treatment, not only for alleviating depression, but also for correcting the body's dysfunction that triggers depressive symptoms (Zhang and Cheng, 2019).

\section{TCM IN DEPRESSION TREATMENT}

The conventional antidepressants with single targets are insufficient and far from ideal. TCM has historically been used to treat depression up till today in clinical practice, particularly in Asia. TCM is a holistic medicine, which emphasizes the integrity of body and environmental effects on the internal homeostasis. In TCM, depression is thought to result from "vital energy" deficiency that is caused by dysfunction of multiple physiological systems in the body, such as dysregulation of blood circulation, inflammation, or "dampness and phlegm" (Ye et al., 2019). Strengthening "vital energy" is its healing principle, but correction of imbalance in other physiological systems by stimulating blood circulation, restraining inflammation, or removing "phlegm and dampness" is also needed (Feng et al., 2016).

It is well-known that a TCM herbal formula is more effective than single herbal molecules or herbs in clinical practice. There are numerous TCM herbal formulas, such as Kai-Xin-San (KXS), that have been usually used for depression treatment. Each formula is a mixture of multiple herbs that are proposed to act on diverse pathological targets simultaneously. Their composition and dosage rely on symptoms of individual patients. The holistic, multidrug, and multitarget nature of TCM fits well with the healing idea of systems medicine in the treatment of complex diseases, such as depression.

During the past two decades, efforts have been made to understand TCM in depression treatment; however, many fundamental questions regarding their mechanisms of action remain to be addressed. Previous studies have focused on revealing the mechanism of action at the molecular level by using either single herbal molecules or extracts from single herbs because the constituent complexity and drug-drug interactions of an entire formula often obstruct to uncover the molecular mechanism of action. However, it is vital to integrate the mechanism of action from the molecule level into the systems level in order to elucidate the system-wide mechanism of action of an herbal formula. The remarkable progress in our understanding of neurobiology of depression provides an opportunity to interpret the mechanism of action of herbal formulas at the systems level.

Studies have revealed many divergent biological systems that are implicated in the pathophysiology of depression (Duman et al., 2016). These findings have provided numerous pharmacological targets that have been translated into the foundation to reveal the mechanism of action of antidepressants. In this Mini Review, we review and discuss the influences of herbal antidepressants on the pathological systems in the CNS (Figure 1), as well as the pharmacological approaches to integrate the mechanism of action of TCM antidepressant formulas from the molecular level into the systems level. A preliminary literature search for TCM herbal antidepressants was performed on the PubMed, Ovid, Google Scholar, and China National Knowledge Infrastructure and WanFang database by using keywords (Traditional Chinese medicine and depression or antidepressant and the term corresponding to the specific mechanism of action, such as monoamine transmission, HPA axis, BDNF, or rapid-acting antidepressant) without language restriction. Abstracts under the same mechanism of action category were independently screened by authors to identify articles of interest and full articles were further selected as representatives with a priority for single herbal molecules or herbs in the latest publications. Given space limitations, this review is not comprehensive; rather we give a few representative herbal molecules that are related to KXS (except for glutamate transmission) and well interpreted at the molecular level, and other herbal molecules are listed with a structural classification in Table $\mathbf{1}$.

\section{MOLECULAR MECHANISM OF ACTION OF TCM HERBAL ANTIDEPRESSANTS}

\section{Monoamine Transmissions}

In monoamine hypothesis, depression is caused by an impairment of monoamine neurotransmissions. Inhibition of monoamine reuptake transporters increases the availability of monoamines in the synaptic cleft and subsequently enhances monoamine transmissions. The monoamine reuptake transporters for serotonin (5-HT) and norepinephrine (NE) are the major targets for current available antidepressants. In addition, a host of proteins including monoamine metabolic enzymes and postsynaptic monoamine receptors are also involved in monoamine transmissions. The monoamine-based inhibitors enhance 5-HT or NE transmission, resulting in alterations in firing activity of dorsal raphe nucleus or locus coeruleus through different mechanisms (Mansari et al., 2010; Araragi et al., 2013).

It can be exemplified with the study on Polygala tenuifolia Willd., which has been shown to exert expectorant, tonic, tranquilizer and antipsychotic efficacies in clinical practice and can be seen in several empirical formulas for depression treatment, such as Kai-Xin-San (KXS) (Hu et al., 2011). Its mechanism of action in depression treatment had not been well understood until Yuanzhi-1, a triterpenoid saponin isolated from Polygala tenuifolia Willd., has recently been identified to be a triple monoamine reuptake inhibitor with a high potency (Jin et al., 2015). Moreover, Yuanzhi-1 and its several derivates have been shown to exert comparable antidepressant-like activities 


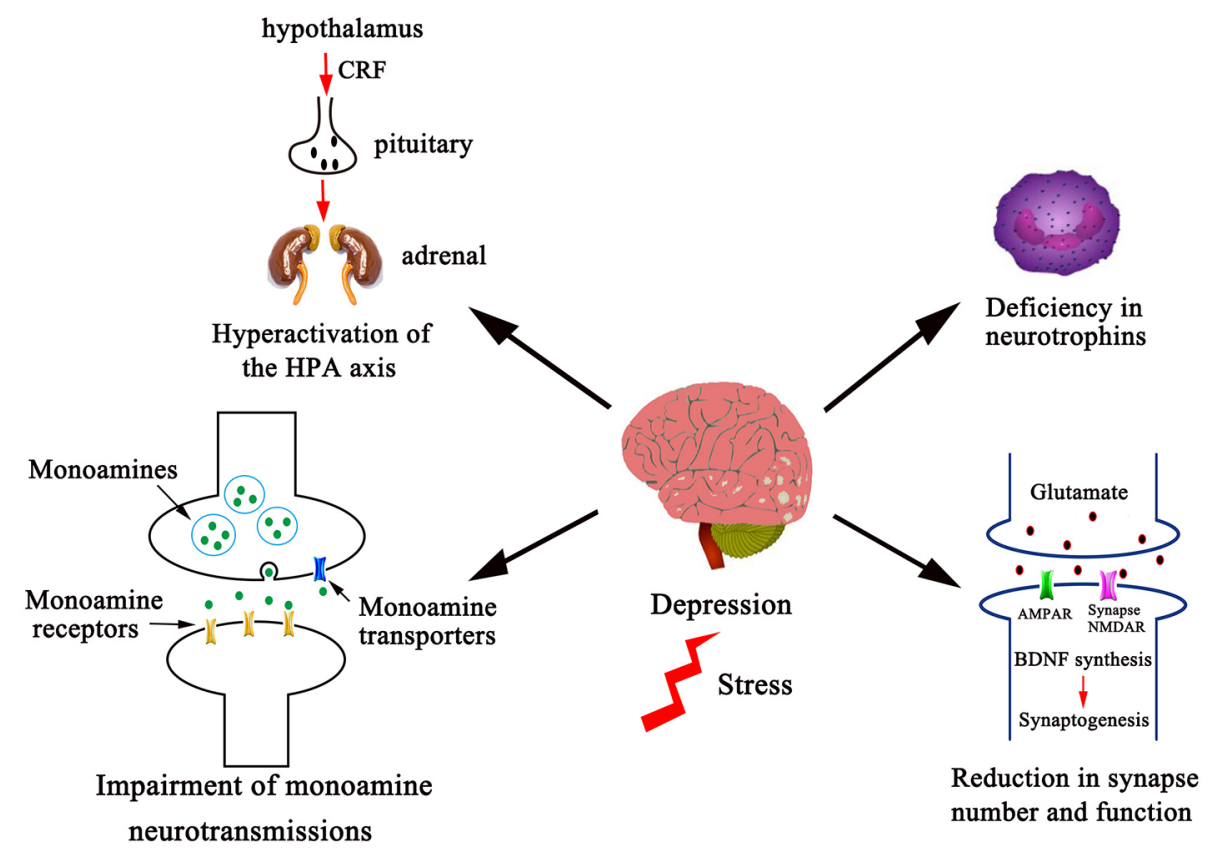

FIGURE 1 | Several divergent systems in the CNS are involved in the pathophysiology of depression. The pathophysiological systems in the CNS that herbal antidepressants are proposed to act on include monoamine neurotransmissions, the HPA axis, neurotrophins, and synapse number and function as shown. Dysfunction of these systems leads to increased incidence of depression. Correspondingly, antidepressant discovery efforts toward these systems have provided numerous pharmacological targets, which include enhancement of monoaminergic transmissions, dehyperactivation of HPA axis, elevation of neurotrophic factor expression, and stimulation of glutamatergic transmission. Given space limitations, other factors in the pathophysiology of depression, such as the proinflammatory cytokines, the gastrointestinal system, ovarian steroids, vascular endothelial growth factor, and gene polymorphisms are not shown and discussed in this Mini Review.

with the conventional antidepressant, duloxetine, in animal behavioral models (Jin et al., 2014). However, lack of selectivity for 5-HT or NE reuptake of these triterpenoid saponins increases our concerns about their addictive side effects caused by elevating synaptic concentrations of dopamine. Hence, it is interesting to know if there are some constituents that show antagonistic interactions with the triterpenoid saponins to normalize their effects on dopamine transmission in Polygala tenuifolia Willd.containing formulas. In addition to its influence on monoaminergic systems, previous studies have shown that an oligosaccharide esters-enriched fraction YZ50 produces an antidepressant action in animal models through the HPA axis (Hu et al., 2010; Liu et al., 2010). These results indicate that Polygala tenuifolia Willd. possesses various antidepressant actions through multiple mechanisms. Therefore, further study to reveal the synergistic interactions between the constituents is required in order to integrate their effects on multiple biological systems into the system-wide mechanism of action of Polygala tenuifolia Willd.

Besides Yuanzhi-1 and its derivates, many other herbal molecules have also been shown to produce antidepressant-like activities through their impacts on monoamine transmission, although their pharmacological profiles have not been clearly revealed yet (Table 1). These compounds, ranging from polyphenols, saponins, alkaloids, and flavonoids, have no structural preference in their mechanisms of action underlying enhancement of monoamine transmissions.

\section{The HPA Axis}

Stress leads to activation of the HPA axis usually reflected in high levels of glucocorticoids, which subsequently impair neuronal survival and neurogenesis and thereby result in depressive symptoms (Keller et al., 2017). It should be emphasized that the communications exist between the HPA axis and the CNS, endocrine, or immune system by neural, hormonal, or inflammatory interactions, and that these systems integrate into a network that underlies antidepressant action. For instance, monoamine-based antidepressants can not only reverse stress-induced hyperactivity of the HPA axis, but also attenuate the inflammatory changes by reducing the release of proinflammatory cytokines from activated microglia (Leonard, 2014; Ramirez and Sheridan, 2016; Simões et al., 2019). Similarly, agents that eliminate inflammatory effects also exert an antidepressant-like activity in animal models through the communication between the CNS and immune system (Zunszain et al., 2011). Furthermore, agents that directly target the HPA axis, such as glucocorticoid receptor antagonists, vasopressin receptor antagonists, and corticotropin-releasing hormone receptor antagonists, could also be effective antidepressants by blocking receptor activities to terminate the 


\begin{tabular}{|c|c|c|c|c|c|c|c|}
\hline Structural category & Herbal constituents & Herbs & Mechanism of action & Models & Administration dosage & $\begin{array}{l}\text { Treatment } \\
\text { time }\end{array}$ & Reference \\
\hline \multirow[t]{18}{*}{ Saponins } & Total saponins & Panax ginseng C. A. Mey. & The HPA axis/BDNF & CUMS rats & $12.5,25,50$ mg/kg, i.g. & 6 weeks & (Liu et al., 2011) \\
\hline & Sarsasapogenin & Anemarrhena asphodeloides Bunge & Monoamine & CUMS mice & $12.5,25,50$ mg/kg, p.o. & 14 days & (Ren et al., 2006) \\
\hline & Ginsenoside $\mathrm{Rb}_{1}$ & Panax ginseng C. A. Mey. & Monoamine & mice & 4, 8, 16 mg/kg, p.o. & 7 days & (Wang et al., 2017) \\
\hline & & & & & 5, 10, 20 mg/kg, p.o. & $60 \mathrm{~min}$ & (Wang et al., 2018b) \\
\hline & & & BDNF & CUMS mice & 20 mg/kg, p.o. & 21 days & (Wang et al., 2019a) \\
\hline & Ginsenoside Rg3 & Panax ginseng C. A. Mey. & The HPA axis & CUS rats & 20,40 mg/kg, i.g. & 14 days & (Xu et al., 2018) \\
\hline & & & BDNF & CSDS mice & 10, 20 mg/kg, i.p. & 14 days & (You et al., 2017) \\
\hline & & $\begin{array}{l}\text { Panax notoginseng (Burkill) F. H. Chen ex } \\
\text { C. Chow \& W. G. Huang }\end{array}$ & $\begin{array}{l}\text { Glutamate transmission/ } \\
\text { BDNF }\end{array}$ & CMS mice & 50, 100, 150 mg/kg, i.g. & 4 weeks & (Zhang et al., 2017) \\
\hline & Ginsenoside Rg1 & Panax ginseng C. A. Mey. & BDNF & CUMS rats & 40 mg/kg, i.p. & 5 weeks & (Liu et al., 2016) \\
\hline & Ginsenoside Rg5 & Panax ginseng C. A. Mey. & BDNF & CSDS mice & 5, 10, 20, 40 mg/kg, i.p. & 14 days & (Xu et al., 2017a) \\
\hline & Saikosaponin A & Bupleurum chinense DC. & Monoamine & CUMS rats & $50 \mathrm{mg} / \mathrm{kg}$, i.g. & 4 weeks & (Guo et al., 2020) \\
\hline & Saikosaponin D & Bupleurum chinense DC. & The HPA axis & CUMS rats & 0.75 and $1.50 \mathrm{mg} / \mathrm{kg}$, i.g. & 21 days & (Li et al., 2017) \\
\hline & YY-21 & Anemarrhena asphodeloides Bunge & BDNF & CMS rats & 10 mg/kg, i.g. & 3 weeks & (Guo et al., 2016) \\
\hline & $Y Y-23$ & Anemarrhena asphodeloides Bunge & Glutamate transmission & CMS mice & 20 mg/kg, i.g. & 3 weeks & (Zhang et al., 2016) \\
\hline & Yuanzhi-1 & Polygala tenuifolia Willd. & Monoamine & CMS rats & $2.5,5,10 \mathrm{mg} / \mathrm{kg}$, p.o. & 38 days & (Jin et al., 2015) \\
\hline & YZ-50 & Polygala tenuifolia Willd. & BDNF & CMS rats & 140 and 280 mg/kg, i.g. & 28 days & (Hu et al., 2010) \\
\hline & Icariin & Epimedium brevicornu Maxim. & The HPA axis & SDM mice & 25 and 50 mg/kg, i.g. & 28 days & (Wu et al., 2011) \\
\hline & 20(S)-protopanaxadiol & Panax ginseng C. A. Mey. & BDNF & CSDS mice & 20 and $40 \mu \mathrm{mol} / \mathrm{kg}$, i.p. & 14 days & (Jiang et al., 2019) \\
\hline \multirow[t]{5}{*}{ Glycosides } & Salidroside & Rhodiola rosea L. & The HPA axis/BDNF & $\begin{array}{l}\text { Behavioral despair } \\
\text { rats }\end{array}$ & 20, 40 mg/kg, p.o. & 14 days & (Yang et al., 2014) \\
\hline & Total glycosides & Paeonia lactiflora Pall. & BDNF & CORT-induced rats & 160 mg/kg, p.o. & 21 days & (Mao et al., 2012) \\
\hline & Gentiopicroside & Gentiana lutea L. & Glutamate transmission & $\begin{array}{l}\text { Reserpine-induced } \\
\text { mice }\end{array}$ & 50, 100, 200 mg/kg, i.g. & 3 days & (Liu et al., 2014b) \\
\hline & Gastrodin & Gastrodia elata Bl. & BDNF & CUS rats & 50, 100, 200 mg/kg, i.p. & 14 days & (Zhang et al., 2014b) \\
\hline & Paeoniflorin & Paeonia lactiflora Pall. & BDNF & CUMS mice & 20 mg/kg, i.p. & 30 days & (Liu et al., 2019) \\
\hline \multirow[t]{9}{*}{ Flavonoids } & Flavonoid Extract & Apocynum venetum $\mathrm{L}$. & BDNF & $\begin{array}{l}\text { CORT-induced PC12 } \\
\text { Cells }\end{array}$ & $25,50,100 \mu \mathrm{g} / \mathrm{ml}$ & 48 hours & (Zheng et al., 2011) \\
\hline & Pueraria isoflavone & Pueraria lobate (Willd.) Ohwi & BDNF & Ovariectomy mice & 10 and $100 \mathrm{mg} / \mathrm{kg}$ & 8 weeks & $\begin{array}{l}\text { (Tantipongpiradet } \\
\text { et al., 2019) }\end{array}$ \\
\hline & Puerarin & Pueraria lobate (Willd.) Ohwi & Monoamine/the HPA axis & CUS rats & 60 and 120 mg/kg, i.g. & 20 days & (Qiu et al., 2017) \\
\hline & & & BDNF & $\begin{array}{l}\text { Perimenopausal } \\
\text { depression mice }\end{array}$ & $30,60,120 \mathrm{mg} / \mathrm{kg}$, i.g. & $\begin{array}{l}8 \text { or } 14 \\
\text { days }\end{array}$ & (Zhao et al., 2017) \\
\hline & Curcumin & Curcuma longa $\mathrm{L}$. & $\begin{array}{l}\text { Monoamine/the HPA axis/ } \\
\text { BDNF }\end{array}$ & CUMS rats & $2.5,5$ and $10 \mathrm{mg} / \mathrm{kg}$, p.o. & 21 days & (Xu et al., 2006) \\
\hline & & & & CUMS rats & 40 mg/kg, i.p. & 6 weeks & (Zhang et al., 2014a) \\
\hline & & & & WKY rats & 50, 100, 200 mg/kg, i.p. & 10 days & (Hurley et al., 2013) \\
\hline & Genistein & Glycine $\max (\mathrm{L}$.$) Merr.$ & Monoamine & Mice & 5, 15, 45 mg/kg, p.o. & 3 weeks & (Hu et al., 2017) \\
\hline & Baicalein & Scutellaria baicalensis Georgi & BDNF & CMS rats & 1, 2, 4 mg/kg, i.p. & 21 days & (Xiong et al., 2011) \\
\hline \multirow[t]{6}{*}{ Alkaloids } & Isorhynchophylline & uncaria rhynchophylla (Miq.) Miq. ex Havil. & Monoamine & Mice & $10,20,40$ mg/kg, i.g. & 7 days & (Xian et al., 2017) \\
\hline & Berberine Chloride & Berberis aristata Linn. & Monoamine & Male albino mice & 5, 10, 20 mg/kg, i.p & 15 days & $\begin{array}{l}\text { (Kulkarni and Dhir, } \\
\text { 2008) }\end{array}$ \\
\hline & Piperine & Piper Nigrum L. Piper longum L. & BDNF & CORT-induced mice & 5,10 mg/kg, i.p. & 21 days & (Mao et al., 2014) \\
\hline & Tetrandrine & Stephania tetrandra S. Moore & Monoamine/BDNF & CUMS rats & $10,20,40$ mg/kg, i.g. & 2 weeks & (Gao et al., 2013) \\
\hline & Total alkaloid & Aconitum carmichaelii Debeaux & BDNF & Ovariectomized mice & 10,30 mg/kg, i.g. & 7 days & (Liu et al., 2012) \\
\hline & Scopolamine & Solanaceae Juss. & Glutamate transmission & $\begin{array}{l}\text { Gad1-Cre Camk2a- } \\
\text { Cre mice }\end{array}$ & $25 \mu \mathrm{g} / \mathrm{kg}$, i.p. & $\begin{array}{l}48 \text { hours } / 3 \\
\text { times }\end{array}$ & (Wohleb et al., 2016) \\
\hline
\end{tabular}




\begin{tabular}{|c|c|c|c|c|c|c|c|}
\hline & & & & & & & \\
\hline & Huperzine A & Huperzia Bernh. & $\begin{array}{l}\text { Monoamine/BDNF/ } \\
\text { Glutamate transmission }\end{array}$ & CUMS rats & 0.05 and $0.15 \mathrm{mg} / \mathrm{kg}$, i.g. & 4 weeks & $\begin{array}{l}\text { (Zheng et al., 2016; Du } \\
\text { et al., 2017) }\end{array}$ \\
\hline \multirow[t]{4}{*}{ Carbohydrates } & Oligosaccharide & Morinda officinalis How & The HPA axis & $\begin{array}{l}\text { CORT-induced PC12 } \\
\text { cells }\end{array}$ & $5,10,125,500 \mu \mathrm{M}$ & 5 days & (Li et al., 2003) \\
\hline & & & & CUS mice & $12.5,25,50 \mathrm{mg} / \mathrm{kg}$, i.g. & 14 days & (Xu et al., 2017b) \\
\hline & Fuzi polysaccharide 1 & Aconitum carmichaelii Debeaux & BDNF & Mice & 50, $100 \mathrm{mg} / \mathrm{kg}$, i.p. & 14 days & (Yan et al., 2010) \\
\hline & Chiisanoside & Acanthopanax Miq. & BDNF & LPS-induced mice & 2.5 and $5 \mathrm{mg} / \mathrm{kg}$, i.p. & 7 days & (Bian et al., 2018) \\
\hline \multirow{13}{*}{$\begin{array}{l}\text { Anthraquinones } \\
\text { Terpenes and } \\
\text { Phenylpropanoids }\end{array}$} & Emodi & Rheum palmatum L. & BDNF & CUMS mice & $20,40,80 \mathrm{mg} / \mathrm{kg}$, i.g & 21 days & (Li et al., 2014) \\
\hline & Resveratrol & Polygonum cuspidatum Siebold et Zucc. & Monoamine & depression mice & 30 mg/kg, p.o. & 3 weeks & (Zhao et al., 2014) \\
\hline & & & The HPA axis/BDNF & Mice & 20, 40, 80 mg/kg, i.p. & 21 days & (Wang et al., 2013) \\
\hline & & & BDNF & $\begin{array}{l}\text { LPS-induced mice/ } \\
\text { CUMS rats }\end{array}$ & 80 mg/kg, i.p. & $\begin{array}{c}7 \text { days } / 5 \\
\text { weeks }\end{array}$ & $\begin{array}{l}\text { (Liu et al., 2014a; Ge } \\
\text { et al., 2015) }\end{array}$ \\
\hline & Trans-resveratrol & polygonum cuspidatum Siebold et Zucc. & Monoamine & CUS rats & 40, 80 mg/kg, i.g. & 21 days & (Yu et al., 2013) \\
\hline & Rosmarinic acid & Perilla frutescens (L.) Britt. & BDNF & CUS rats & 5 and $10 \mathrm{mg} / \mathrm{kg}$, i.p. & 14 days & (Jin et al., 2013) \\
\hline & Crocin & Crocus sativus $\mathrm{L}$. & BDNF & Rats & $12.5,25,50 \mathrm{mg} / \mathrm{kg}$, i.p. & 21 days & $\begin{array}{l}\text { (Vahdati Hassain et al., } \\
\text { 2014) }\end{array}$ \\
\hline & Cucurbitacin Ila & Hemsleya amabilis Diels & BDNF & CUMS mice & $2.5,5 \mathrm{mg} / \mathrm{kg}$, i.p. & 5 weeks & (Zhou et al., 2017) \\
\hline & Hyperforin & Hypericum perforatum L. & BDNF & mice & $4 \mathrm{mg} / \mathrm{kg}$, i.p. & 4 weeks & (Gibon et al., 2013) \\
\hline & & & Glutamate transmission & $\begin{array}{l}\text { Cortical neurons of } \\
\text { rats }\end{array}$ & $10 \mu \mathrm{M}$ & 9-12 days & (Kumar et al., 2006) \\
\hline & Bakuchiol analogs & Psoralea corylifolia Linn. & Monoamine & $\mathrm{Tr}-\mathrm{CHO}$ cells & $0.03-333 \mu \mathrm{M}$ & $20 \mathrm{~min}$ & (Zhao et al., 2008) \\
\hline & Honokiol & Magnolia officinalis Rehd. et Wils. & The HPA axis/BDNF & CUMS rats & 2, 4, $8 \mathrm{mg} / \mathrm{kg}$, i.g. & 21 days & (Wang et al., 2018a) \\
\hline & Macranthol & Illicium dunnianum Tutch. & BDNF & CUMS mice & 10, 20, 40 mg/kg, p.o. & 5 weeks & (Li et al., 2013) \\
\hline
\end{tabular}

Herbal constituents are listed according to their structural category and their sources, mechanism of action, animal models, and administration dosage and time are also given. Although TCM formulas have been shown to work more efficiently than single constituents or herbs in clinical practice, single molecules or herbs are often used for interpreting the mechanism of action at the molecular level due to the constituent complexity and drug-drug interactions of TCM formulas. For understanding the mechanism of action of a TCM formula at the systems level, it is essential to integrate the molecular mechanism into the system-wide mechanism of action. The representative TCM formulas in depression treatment are, but no limited to, Xiao-Yao-San (Chen et al., 2008), Kai-Xin-San (Fu et al., 2020), Jie-Yu-Wan (Feng et al., 2018), Shu-Yu-San (Chen et al., 2012), Chaihu-Jia-Longgu-Muli-Tang (Li et al., 2011), and so on. CUMS, chronic unpredictable mild stress;

CSDS, chronic social defeat stress; CMS, chronic mild stress; SDM, social defeat model; CORT, corticosterone; CUS, chronic unpredictable stress; WKT, Wistar Kyoto; LPS, lipopolysaccharides. 
consequence of hormone secretions due to stress-induced hyperactivity of the HPA axis (Menke, 2019).

Ginsenoside Rg3, a protopanaxadiol ginsenoside from Panax ginseng C. A. Mey., has been recently reported to exert anxiolytic and antidepressant-like activities through dehyperactivation of the HPA axis by reducing corticotropin releasing hormone, corticosterone and adrenocorticotropic hormone in chronic unpredictable stress (CUS) animal models (Xu et al., 2018). Interestingly, a previous study demonstrated that this compound produces anti-inflammatory activities by reducing the level of inflammatory cytokines in the lipopolysaccharideinduced mice (Kang et al., 2017). This phenomenon of one herbal molecule with multiple functions is often seen in the study of herbal antidepressants, possibly due to either the crosstalk between the biological systems or nonspecific interactions with multiple systems.

Other herbal constituents have also been reported to produce antidepressant-like activities through their effects on the HPA axis (Table 1). However, all of these herbal constituents have not been clarified whether their effects are direct or indirect. We cannot exclude one scenario that herbal constituents could directly act on one biological system and then induce the responses from the HPA axis due to the cross-talk between these biological systems. Thus, it could obscure the pharmacological targets that herbal constituents actually act on and mislead us to understand their molecular mechanisms of action. Therefore, further studies are needed to clarify the contribution of herbal constituents to the system-wide antidepressant action.

\section{Neurotrophins}

Brain-derived neurotrophic factor (BDNF) deficiency contributes to the pathophysiology of depression (Duman et al., 2019). Experimental observations have demonstrated that stress-induced downregulation of cAMP response element binding protein (CREB) mRNA level, and its phosphorylation, BDNF expression, and neurogenesis can be reversed by antidepressant treatments (Kishi et al., 2018). This raises the possibility that an agent that directly stimulates BDNF singling cascade might be an effective antidepressant. The potential drug targets in BDNF cascade should enhance CREB activity and BDNF expression, activate BDNF receptor TrkB, or stimulate post-receptor signaling cascades such as Ras-Raf-ERK, PI3KAkt, and PLC $\gamma$.

Recent studies have demonstrated that chronic administration ( $40 \mathrm{mg} / \mathrm{kg}$, 5 weeks) of ginsenoside Rg1, a protopanaxatriol type of ginsenoside, reverses behavioral abnormality and downregulation of the phosphorylation level of CREB and BDNF expression in the prefrontal cortex induced by chronic unpredictable mild stress (CUMS) in rats (Zhu et al., 2016a; Yu et al., 2018). In addition, ginsenoside $\operatorname{Rg} 1$ has also been shown to exert neuroprotective effects by suppressing inflammatory pathway activity, inhibiting neuronal apoptosis, and stimulating synaptic-related protein expression, such as CREB, BDNF, PSD-95, and synaptophysin (Fan et al., 2018). Ginsenoside Rg5, a protopanaxadiol ginsenoside, has been reported to exert an antidepressant-like activity by reversing the chronic social defeat-induced decrease in hippocampal BDNF expression and phosphorylation of TrkB (Xu et al., 2017a).

Several other herbal constituents have also been reported to produce antidepressant-like activities through BDNF signaling cascade (Table 1). It will be interesting to know if these herbal constituents directly act on BDNF signaling cascade and what targets they specifically interact with. Hence, more in-depth studies are required to address these questions, which are important for our understanding of their mechanistic details in order to further refine the use of these herbal antidepressants.

\section{Glutamate Transmission}

Glutamate transmission has recently received the most attention in the development of rapid-acting antidepressant agents. These agents, such as NMDA receptor channel blockers and its positive allosteric modulators and acetylcholine muscarinic (AChM) receptor antagonists, enhance glutamate transmission, subsequently increase BDNF release and synapse function, thus rapidly reverse stress-induced synaptic abnormalities (Koike et al., 2011; Li et al., 2011; Burgdorf et al., 2013). Ketamine, a NMDA receptor antagonist, has been shown to produce rapid antidepressant actions (Diazgranados et al., 2010; Murrough et al., 2013), and its $S(+)$ enantiomer, esketamine was approved in 2019 as the first rapid-acting antidepressant to treat severe depression.

The Solanaceae Juss. family of herbs such as Datura metel L., Hyoscyamus niger L., and Datura stramonium L. contain psychedelic tropane alkaloids used for surgical anesthesia in ancient TCM practice. Scopolamine, a major tropane alkaloid isolated from these herbs, can readily cross the brain blood barrier into the CNS to inhibit AChM1 receptor (Klinkenberg and Blokland, 2010). Recent studies have demonstrated that a single dose of scopolamine $(25 \mu \mathrm{g} / \mathrm{kg})$ exerts rapid antidepressant actions within days in rats (Furey et al., 2010; Drevets et al., 2013). Its antidepressant actions have been revealed to be mediated through blockade of AChM1 receptor on GABA interneurons and subsequently to increase in glutamate transmission and function of spine synapse (Voleti et al., 2013; Wohleb et al., 2016; Fogaça et al., 2019).

In addition to scopolamine, two herbal formulas, Yueju pill and Chaihu-jia-Longgu-Muli-tang, have recently been reported to exert rapid-acting antidepressant-like activities in animal models. A dose of ethanol extracts from Yueju pill $(3 \mathrm{~g} / \mathrm{kg})$ rapidly attenuated depressive-like behaviors, increased hippocampal BDNF expression, activated prefrontal AktmTOR signaling, and downregulated NR1 expression within days (Xue et al., 2013; Tang et al., 2015; Xia et al., 2016). Chaihu-jia-Longgu-Muli-tang (a single dose of $2.1 \mathrm{~g} / \mathrm{kg}$ ) has also been shown to produce a rapid antidepressant-like activity in olfactory bulbectomization mice through activation of AktmTOR signaling and normalization of AMPA receptor/NMDA receptor ratio in PFC (Wang et al., 2019b). In addition, these formulas have previously been shown to produce antidepressant actions through monoaminergic systems as well as the HPA axis in chronic animal models (Mizoguchi et al., 2003; Li et al., 2012; Wang et al., 2013). It is reasonable 
that these formulas possess multiple antidepressant actions through several underlying mechanisms due to its multidrug property, but further study is needed to reveal the synergistic interaction between its rapid antidepressant action and other underlying mechanisms.

\section{TRANSITION FROM MOLECULES TO SYSTEMS}

Studies have revealed numerous pathological factors that are involved in the pathophysiology of depression (Krishnan and Nestler, 2008). In addition to the factors or systems in the CNS mentioned above, other notable factors include proinflammatory cytokines, ovarian steroids, gastrointestinal system and microbiome, and vascular endothelial growth factor (Schmidt et al., 2011). The CNSorientated and single target antidepressants can only be used to alleviate depressive symptoms, but not to correct dysfunction of the pathological factors in other biological systems. On the other hand, the holistic and multidrug approach of TCM formulation is proposed to simultaneously act on multiple targets across various systems in the pathophysiology of depression. Therefore, it is essential to investigate the mechanism of action at the systems level for better understanding of TCM formulations in depression treatment.

It is a challenge to investigate the pharmacology of any TCM formulation at the systems level, including synergistic interaction and compatibility between herbs within multiherb combinations, due to the fact that not all potentially bioactive ingredients from any given TCM formula were identified and that their pharmacological properties were not thoroughly defined (Zhou et al., 2016). However, several studies have successfully been conducted to examine the synergistic, additive, and antagonistic interactions of herb pairs in complex TCM formulas (Adams et al., 2006; Yi and Wetzstein, 2011; Wang et al., 2012). KXS, a combination of four herbs (Panax ginseng C. A. Mey., Polygala tenuifolia Willd., Acorus tatarinowii Schott, and Poria cocos (Schw.) Wolf), is an empirical formula for depression treatment. A recent study has been performed to optimize the compatibility of herb pairs in KXS by examining the activation of neurofilament expression in PC12 cells (Yan et al., 2015). In this study, Panax ginseng C. A. Mey. and Polygala tenuifolia Willd. were placed as an herb pair with a function in invigorating "vital energy", while Acorus tatarinowii Schott and Poria cocos (Schw.) Wolf were assigned to another pair to eliminate "dampness and phlegm". The study showed that an optimized KXS with an herb pair ratio (1:5) produced the greatest capability in promoting the expression of neurofilament and that two herb pairs exert strong synergistic interactions in stimulating neuronal differentiation.

KXS has previously been demonstrated to exert antidepressant actions through multiple mechanisms across biological systems, including increase in monoamine availability (Zhou et al., 2012; Zhu et al., 2012), activation of hippocampal synaptogenesis and BDNF signaling cascade (Zhu et al., 2016b; Yan et al., 2016; Zhu et al., 2017), dehyperactivation of the HPA axis (Dang et al., 2009), and enhancement of lipid metabolism (Zhou et al., 2020). It is evident that the antidepressant efficiency of KXS results from the synergistic interactions between individual herbs, although each herb showed the potent effect in depression treatment (Yan et al., 2015). A recent study has been conducted to screen the proteins in response to KXS administration ( $0.6 \mathrm{~g} / \mathrm{kg}, 14$ days) across biological systems by using quantitation-based proteomics (Dong et al., 2020). In this study, total 33 proteins with altered expression levels were identified to be associated with KXS treatment. Functional analysis further revealed that these proteins are implicated in glutamate signaling, synaptic plasticity, metabolic process, cell survival process, and BDNF, mTORC1, and cAMP pathways. These studies indicated that KXS exerts antidepressant actions across multiple biological systems and provided pharmacological approaches to our understanding of the mechanism of action of KXS at the systems level.

\section{DISCUSSION}

The studies, in which the herbal constituents or single molecules were used for exploring the mechanism of action at the molecular level, have provided a foundation to understand the system-wide mechanism of action of an herbal formula. Systems pharmacology studies drugs, drug targets, and drug effects at the systems level and reveals all responses across various biological systems to the pharmacological action of drugs (Zhao and Iyengar, 2012). Therefore, application of systems pharmacology approaches to TCM study is vital for our understanding of the system-wide mechanism of action of herbal formulas.

Although single herbal molecules or herbs show the potent action in depression treatment, an herbal composite formula is used clinically, rather than a single form. The empirical formulas have been proven to have greater efficacy and safety than single drugs in clinical practice, possibly due to their synergistic interactions and mutual detoxification (Ung et al., 2007). The synergy of multiple herbs in an herbal formula could be triggered by the interactions between herbal molecules from different herbs or between the pharmacological targets across biological systems that herbal molecules specifically act on, and this phenomenon could be interpreted through systems pharmacology study of TCM herbal formulations.

We should acknowledge that a major challenge is lack of an integrated database including all interactions between the pathological factors across biological systems in the pathophysiology of depression, although efforts have been made to identify the specific interactions within the CNS (Pittenger and Duman, 2008). The effects of other biological systems on the CNS remain to be thoroughly studied in order to reveal the interactions between the pathological factors in different biological systems. With such a database, we will be able to promote our study from the molecular level into the systems level, which, in turn, could facilitate the integration of other biological systems with the CNS in depression treatment. 
In summary, integration of the studies at the molecular level into the systems level not only represents a trend in TCM study but also promotes our understanding of the system-wide mechanism of action of herbal formulas. With many available techniques in systems biology, neurobiology, and pharmacology, the study of TCM will assist in developing future medications or approaches for systematic and effective depression treatment.

\section{AUTHOR CONTRIBUTIONS}

CL, JH, Y-CC, and Y-WZ wrote the manuscript.

\section{REFERENCES}

Adams, L. S., Seeram, N. P., Hardy, M. L., Carpenter, C., and Heber, D. (2006). Analysis of the interactions of botanical extract combinations against the viability of prostate cancer cell lines. Evid. Based. Complement Alternat Med. 3 , 117-124. doi: 10.1093/ecam/nel001

Araragi, N., Mlinar, B., Baccini, G., Gutknecht, L., Lesch, K. P., and Corradetti, R. (2013). Conservation of 5-HT1A receptor-mediated autoinhibition of serotonin (5-HT) neurons in mice with altered 5-HT homeostasis. Front. Pharmacol. 4, 97. doi: 10.3389/fphar.2013.00097

Bian, X., Liu, X., Liu, J., Zhao, Y., Li, H., Cai, E., et al. (2018). Study on antidepressant activity of chiisanoside in mice. Int. Immunopharmacol. 57, 33-42. doi: 10.1016/j.intimp.2018.02.007

Burgdorf, J., Zhang, X., Nicholson, K. L., Balster, R. L., Leander, J. D., Stanton, P. K., et al. (2013). GLYX-13, a NMDA receptor glycine-site functional partial agonist, induces antidepressant-like effects without ketamine-like side effects. Neuropsychopharmacology 38, 729-742. doi: 10.1038/npp.2012.246

Chen, J. X., Li, W., Zhao, X., and Yang, J. X. (2008). Effects of the Chinese traditional prescription Xiaoyaosan decoction on chronic immobilization stress-induced changes in behavior and brain BDNF, TrkB, and NT-3 in rats. Cell Mol. Neurobiol. 28 (5), 745-755. doi: 10.1007/s10571-007-9169-6

Chen, L., Chen, M., Wang, F., Sun, Z., Quanzhi, H., Geng, M., et al. (2012). Antidepressant-like effects of shuyusan in rats exposed to chronic stress: effects on hypothalamic-pituitary-adrenal function. Evid. Based. Complement Alternat Med. 2012, 940846. doi: 10.1155/2012/940846

Dang, H., Sun, L., Liu, X., Peng, B., Wang, Q., Jia, W., et al. (2009). Preventive action of Kai Xin San aqueous extract on depressive-like symptoms and cognition deficit induced by chronic mild stress. Exp. Biol. Med. (Maywood) 234 (7), 785-793. doi: 10.3181/0812-RM-354

Diazgranados, N., Ibrahim, L., Brutsche, N. E., Newberg, A., Kronstein, P., Khalife, S., et al. (2010). A randomized add-on trial of an N-methyl-D-aspartate antagonist in treatment-resistant bipolar depression. Arch. Gen. Psychiatry 67 (8), 793-802. doi: 10.1001/archgenpsychiatry.2010.90

Dong, X. Z., Wang, D. X., Zhang, T. Y., Liu, X., Liu, P., and Hu, Y. (2020). Identification of protein targets for the antidepressant effects of Kai-Xin-San in Chinese medicine using isobaric tags for relative and absolute quantitation. Neural Regener. Res. 15 (2), 302-310. doi: 10.4103/1673-5374.265555

Drevets, W. C., Zarate, C. A., and Furey, M. L. (2013). Antidepressant effects of the muscarinic cholinergic receptor antagonist scopolamine: a review. Biol. Psychiatry 73, 1156-1163. doi: 10.1016/j.biopsych.2012.09.031

Du, Y., Liang, H., Zhang, L., and Fu, F. (2017). Administration of Huperzine A exerts antidepressant-like activity in a rat model of post-stroke depression. Pharmacol. Biochem. Behav. 158, 32-38. doi: 10.1016/j.pbb.2017.06.00

Duman, R. S., Aghajanian, G. K., Sanacora, G., and Krystal, J. H. (2016). Synaptic plasticity and depression: new insights from stress and rapid-acting antidepressants. Nat. Med. 22 (3), 238-249. doi: 10.1038/nm.4050

Duman, R. S., Deyama, S., and Fogaça, M. V. (2019). Role of BDNF in the pathophysiology and treatment of depression: Activity-dependent effects distinguish rapid-acting antidepressants. Eur. J. Neurosci. 00, 1-14. doi: $10.1111 /$ ejn.14630

Fan, C., Song, Q., Wang, P., Li, Y., Yang, M., and Yu, S. Y. (2018). Neuroprotective Effects of Ginsenoside-Rg1 Against Depression-Like Behaviors via Suppressing

\section{ACKNOWLEDGMENTS}

This work was supported by Guangdong Basic and Applied Basic Research Foundation (2019A1515011569 to Y-WZ), China Postdoctoral Science Foundation (2019M662844 to CL), and Guangzhou University Research Grants (RD2020054 to Y-WZ and RP2020082 to JH). CL was financially supported by the International Training Program for Outstanding Scientific Research Postdoctoral of Guangdong Province, China. We thank Dr. Ryota Shinohara at the Department of Psychiatry, Yale University School of Medicine for critical reading the manuscript and helpful discussion.

Glial Activation, Synaptic Deficits, and Neuronal Apoptosis in Rats. Front. Immunol. 9, 2889. doi: 10.3389/fimmu.2018.02889

Feng, D. D., Tang, T., Lin, X. P., Yang, Z. Y., Yang, S., Xia, Z. A., et al. (2016). Nine traditional Chinese herbal formulas for the treatment of depression: an ethnopharmacology, phytochemistry, and pharmacology review. Neuropsychiatr. Dis. Treat. 12, 2387-2402. doi: 10.2147/NDT.S114560

Feng, G. K., Ma, X. J., Chen, Y. Y., Bian, G. R., Yang, C., and Gu, B. D. (2018). Effects of Chailong Jieyu Pill on Behavior, Monoamine Neurotransmitters, and Corticosteroid Receptors in a Rat Model of Anxiety Disorder. Evid. Based. Complement Alternat Med. 2018, 5489215. doi: 10.1155/2018/5489215

Fogaça, M. V., Fukumoto, K., Franklin, T., Liu, R. J., Duman, C. H., Vitolo, O. V., et al. (2019). N-Methyl-D-aspartate receptor antagonist d-methadone produces rapid, mTORC1-dependent antidepressant effects. Neuropsychopharmacology 0, 1-9. doi: 10.1038/s41386-019-0501-X

Fu, H., Xu, Z., Zhang, X. L., and Zheng, G. Q. (2020). Kaixinsan, a Well-Known Chinese Herbal Prescription, for Alzheimer's Disease and Depression: A Preclinical Systematic Review. Front. Neurosci. 13, 1421. doi: 10.3389/ fnins.2019.01421

Furey, M. L., Khanna, A., Hoffman, E. M., and Drevets, W. C. (2010). Scopolamine produces larger antidepressant and antianxiety effects in women than in men. Neuropsychopharmacology 35 (12), 2479-2488. doi: 10.1038/npp.2010.131

Gao, S., Cui, Y. L., Yu, C. Q., Wang, Q. S., and Zhang, Y. (2013). Tetrandrine exerts antidepressant-like effects in animal models: role of brain-derived neurotrophic factor. Behav. Brain Res. 238, 79-85. doi: 10.1016/ j.bbr.2012.10.015

Ge, L., Liu, L., Liu, H., Liu, S., Xue, H., Wang, X., et al. (2015). Resveratrol abrogates lipopolysaccharide-induced depressive-like behavior, neuroinflammatory response, and CREB/BDNF signaling in mice. Eur. J. Pharmacol. 768, 49-57. doi: 10.1016/j.ejphar.2015.10.026

Gibon, J., Deloulme, J. C., Chevallier, T., Ladeveze, E., Abrous, D. N., and Bouron, A. (2013). The antidepressant hyperforin increases the phosphorylation of CREB and the expression of TrkB in a tissue-specific manner. Int. J. Neuropsychopharmacol. 16 (1), 189-198. doi: 10.1017/S146114571100188X

Guo, F., Zhang, B., Fu, Z., Ma, Y., Gao, Y., Shen, F., et al. (2016). The rapid antidepressant and anxiolytic-like effects of YY-21 involve enhancement of excitatory synaptic transmission via activation of mTOR signaling in the mPFC. Eur. Neuropsychopharmacol. 26 (7), 1087-1098. doi: 10.1016/ j.euroneuro.2016.05.006

Guo, J., Zhang, F., Gao, J., Guan, X., Liu, B., Wang, X., et al. (2020). Proteomicsbased screening of the target proteins associated with antidepressant-like effect and mechanism of Saikosaponin A. J. Cell Mol. Med. 24 (1), 174-188. doi: $10.1111 / \mathrm{jcmm} .14695$

Hasin, D. S., Sarvet, A. L., Meyers, J. L., Saha, T. D., Ruan, W. J., Stohl, M., et al. (2018). Epidemiology of adult DSM-5 major depressive disorder and its specifiers in the United States. JAMA Psychiatry 75 (4), 336-346. doi: 10.1001/jamapsychiatry.2017.4602

Hu, Y., Liu, P., Guo, D. H., Rahman, K., Wang, D. X., and Xie, T. T. (2010). Antidepressant effects of the extract YZ-50 from Polygala tenuifolia in chronic mild stress treated rats and its possible mechanisms. Pharm. Biol. 48 (7), 794800. doi: 10.3109/13880200903280034

Hu, Y., Liu, M., Liu, P., Guo, D. H., Wei, R. B., and Rahman, K. (2011). Possible mechanism of the antidepressant effect of 3,6'-disinapoyl sucrose from 
Polygala tenuifolia Willd. J. Pharm. Pharmacol. 63 (6), 869-874. doi: 10.1111/ j.2042-7158.2011. 01281.x

Hu, P., Ma, L., Wang, Y. G., Ye, F., Wang, C., Zhou, W. H., et al. (2017). Genistein, a dietary soy isoflavone, exerts antidepressant-like effects in mice: Involvement of serotonergic system. Neurochem. Int. 108, 426-435. doi: 10.1016/ j.neuint.2017.06.002

Hurley, L. L., Akinfiresoye, L., Nwulia, E., Kamiya, A., Kulkarni, A. A., and Tizabi, Y. (2013). Antidepressant-like effects of curcumin in WKY rat model of depression is associated with an increase in hippocampal BDNF. Behav. Brain Res. 239, 27-30. doi: 10.1016/j.bbr.2012.10.049

Jiang, N., Lv, J. W., Wang, H. X., Wang, Q., Lu, C., Yang, Y. J., et al. (2019). Antidepressant-like effects of 20(S)-protopanaxadiol in a mouse model of chronic social defeat stress and the related mechanisms. Phytother. Res. 33 (10), 2726-2736. doi: 10.1002/ptr.6446

Jin, X., Liu, P., Yang, F., Zhang, Y. H., and Miao, D. (2013). Rosmarinic acid ameliorates depressive-like behaviors in a rat model of CUS and Up-regulates BDNF levels in the hippocampus and hippocampal-derived astrocytes. Neurochem. Res. 38 (9), 1828-1837. doi: 10.1007/s11064-013-1088-y

Jin, Z. L., Gao, N., Zhang, J. R., Li, X. R., Chen, H. R., Xiong, J., et al. (2014). The discovery of Yuanzhi-1, a triterpenoid saponin derived from the traditional Chinese medicine, has antidepressantlike activity. Prog. Neuropsychopharmacol. Biol. Psychiatry 53, 9-14. doi: 10.1016/j.pnpbp.2014.02.013

Jin, Z. L., Gao, N., Li, X. R., Tang, Y., Xiong, J., Chen, H. X., et al. (2015). The antidepressant-like pharmacological profile of Yuanzhi-1, a novel serotonin, norepinephrine and dopamine reuptake inhibitor. Eur. Neuropsychopharmacol. 25 (4), 544-556. doi: 10.1016/j.euroneuro.2015.01.005

Kang, A., Xie, T., Zhu, D., Shan, J., Di, L., and Zheng, X. (2017). Suppressive Effect of Ginsenoside Rg3 against Lipopolysaccharide-Induced Depression-Like Behavior and Neuroinflammation in Mice. J. Agric. Food Chem. 65 (32), 6861-6869. doi: 10.1021/acs.jafc.7b02386

Keller, J., Gomez, R., Williams, G., Lembke, A., Lazzeroni, L., Murphy, G. M., et al. (2017). HPA axis in major depression: cortisol, clinical symptomatology and genetic variation predict cognition. Mol. Psychiatry 22 (4), 527-536. doi: $10.1038 / \mathrm{mp} .2016 .120$

Kishi, T., Yoshimura, R., Ikuta, T., and Iwata, N. (2018). Brain-Derived Neurotrophic Factor and Major Depressive Disorder: Evidence from MetaAnalyses. Front. Psychiatry 8, 308. doi: 10.3389/fpsyt.2017.00308

Klinkenberg, I., and Blokland, A. (2010). The validity of scopolamine as a pharmacological model for cognitive impairment: a review of animal behavioral studies. Neurosci. Biobehav. Rev. 34, 1307-1350. doi: 10.1016/ j.neubiorev.2010.04.001

Koike, H., Iijima, M., and Chaki, S. (2011). Involvement of AMPA receptor in both the rapid and sustained antidepressant-like effects of ketamine in animal models of depression. Behav. Brain Res. 224 (1), 107-111. doi: 10.1016/ j.bbr.2011.05.035

Krishnan, V., and Nestler, E. J. (2008). The molecular neurobiology of depression. Nature 455 (7215), 894-902. doi: 10.1038/nature07455

Kulkarni, S. K., and Dhir, A. (2008). On the mechanism of antidepressant-like action of berberine chloride. Eur. J. Pharmacol. 589 (1-3), 163-172. doi: 10.1016/j.ejphar.2008.05.043

Kumar, V., Mdzinarishvili, A., Kiewert, C., Abbruscato, T., Bickel, U., van der Schyf, C. J., et al. (2006). NMDA receptor-antagonistic properties of hyperforin, a constituent of St. John's Wort. J. Pharmacol. Sci. 102 (1), 4754. doi: 10.1254/jphs.fp0060378

Leonard, B. E. (2014). Impact of inflammation on neurotransmitter changes in major depression: an insight into the action of antidepressants. Prog. Neuropsychopharmacol. Biol. Psychiatry 48, 261-267. doi: 10.1016/ j.pnpbp.2013.10.018

Li, Y. F., Gong, Z. H., Yang, M., Zhao, Y. M., and Luo, Z. P. (2003). Inhibition of the oligosaccharides extracted from Morinda officinalis, a Chinese traditional herbal medicine, on the corticosterone induced apoptosis in PC12 cells. Life Sci. 72 (8), 933-942. doi: 10.1016/s0024-3205(02)02331-7

Li, N., Liu, R. J., Dwyer, J. M., Banasr, M., Lee, B., Son, H., et al. (2011). Glutamate $\mathrm{N}$-methyl-D-aspartate receptor antagonists rapidly reverse behavioral and synaptic deficits caused by chronic stress exposure. Biol. Psychiatry 69 (8), 754-761. doi: 10.1016/j.biopsych.2010.12.015

Li, L. F., Lu, J., Li, X. M., Xu, C. L., Yang, J., Qu, R., et al. (2012). Antidepressantlike effects of the saponins extracted from Chaihu-jia-longgu-muli-tang in a rat unpredictable chronic mild stress model. Fitoterapia 83 (1), 93-103. doi: 10.1016/j.fitote.2011.09.017

Li, J., Geng, D., Xu, J., Weng, L. J., Liu, Q., and Yi, L. T. (2013). Antidepressant-like effect of macranthol isolated from Illicium dunnianum tutch in mice. Eur. J. Pharmacol. 707 (1-3), 112-119. doi: 10.1016/j.ejphar.2013.03.010

Li, M., Fu, Q., Li, Y., Li, S., Xue, J., and Ma, S. (2014). Emodin opposes chronic unpredictable mild stress induced depressive-like behavior in mice by upregulating the levels of hippocampal glucocorticoid receptor and brainderived neurotrophic factor. Fitoterapia 98, 1-10. doi: 10.1016/ j.fitote.2014.06.007

Li, H. Y., Zhao, Y. H., Zeng, M. J., Fang, F., Li, M., Qin, T. T., et al. (2017). Saikosaponin D relieves unpredictable chronic mild stress induced depressivelike behavior in rats: involvement of HPA axis and hippocampal neurogenesis. Psychopharmacol. (Berl) 234 (22), 3385-3394. doi: 10.1007/s00213-017-4720-8

Liu, P., Hu, Y., Guo, D. H., Wang, D. X., Tu, H. H., Ma, L., et al. (2010). Potential antidepressant properties of Radix Polygalae (Yuan Zhi). Phytomedicine 17 (10), 794-799. doi: 10.1016/j.phymed.2010.01.004

Liu, L., Luo, Y., Zhang, R., and Guo, J. (2011). Effects of ginsenosides on hypothalamic-pituitary-adrenal function and brain-derived neurotrophic factor in rats exposed to chronic unpredictable mild stress. Zhongguo Zhong Yao Za Zhi 36 (10), 1342-1347. In Chinese.

Liu, L., Li, B., Zhou, Y., Wang, L., Tang, F., Shao, D., et al. (2012). Antidepressantlike effect of Fuzi total alkaloid on ovariectomized mice. J. Pharmacol. Sci. 120 (4), 280-287. doi: 10.1254/jphs.12163fp

Liu, D., Zhang, Q., Gu, J., Wang, X., Xie, K., Xian, X., et al. (2014a). Resveratrol prevents impaired cognition induced by chronic unpredictable mild stress in rats. Prog. Neuropsychopharmacol. Biol. Psychiatry 49, 21-29. doi: 10.1016/ j.pnpbp.2013.10.017

Liu, S. B., Zhao, R., Li, X. S., Guo, H. J., Tian, Z., Zhang, N., et al. (2014b). Attenuation of reserpine-induced pain/depression dyad by gentiopicroside through downregulation of GluN2B receptors in the amygdala of mice. Neuromol. Med. 16 (2), 350-359. doi: 10.1007/s12017-013-8280-8

Liu, Z., Qi, Y., Cheng, Z., Zhu, X., Fan, C., and Yu, S. Y. (2016). The effects of ginsenoside Rg1 on chronic stress induced depression-like behaviors, BDNF expression and the phosphorylation of PKA and CREB in rats. Neuroscience 322, 358-369. doi: 10.1016/j.neuroscience.2016.02.050

Liu, S. C., Hu, W. Y., Zhang, W. Y., Yang, L., Li, Y., Xiao, Z. C., et al. (2019). Paeoniflorin attenuates impairment of spatial learning and hippocampal longterm potentiation in mice subjected to chronic unpredictable mild stress. Psychopharmacol. (Berl) 236 (9), 2823-2834. doi: 10.1007/s00213-019-05257-5

Mansari, M. E., Guiard, B. P., Chernoloz, O., Ghanbari, R., Katz, N., and Blier, P. (2010). Relevance of norepinephrine-dopamine interactions in the treatment of major depressive disorder. CNS Neurosci. Ther. 16 (3), e1-e17. doi: 10.1111/ j.1755-5949.2010.00146.x

Mao, Q. Q., Huang, Z., Ip, S. P., Xian, Y. F., and Che, C. T. (2012). Peony glycosides reverse the effects of corticosterone on behavior and brain BDNF expression in rats. Behav. Brain Res. 227 (1), 305-309. doi: 10.1016/ j.bbr.2011.11.016

Mao, Q. Q., Huang, Z., Zhong, X. M., Xian, Y. F., and Ip, S. P. (2014). Piperine reverses the effects of corticosterone on behavior and hippocampal BDNF expression in mice. Neurochem. Int. 74, 36-41. doi: 10.1016/ j.neuint.2014.04.017

Menke, A. (2019). Is the HPA Axis as Target for Depression Outdated, or Is There a New Hope? Front. Psychiatry 10, 101. doi: 10.3389/fpsyt.2019.00101

Mizoguchi, K., Yuzurihara, M., Ishige, A., Aburada, M., and Tabira, T. (2003). Saiko-ka-ryukotsu-borei-to, a herbal medicine, ameliorates chronic stress induced depressive state in rotarod performance. Pharmacol. Biochem. Behav. 75, 419-425. doi: 10.1016/s0091-3057(03)00131-x

Murrough, J. W., Iosifescu, D. V., Chang, L. C., Al Jurdi, R. K., Green, C. E., Perez, A. M., et al. (2013). Antidepressant efficacy of ketamine in treatment-resistant major depression: a two-site randomized controlled trial. Am. J. Psychiatry 170 (10), 1134-1142. doi: 10.1176/appi.ajp.2013.13030392

Pittenger, C., and Duman, R. S. (2008). Stress, depression, and neuroplasticity: a convergence of mechanisms. Neuropsychopharmacology 33 (1), 88-109. doi: 10.1038/sj.npp.1301574

Qiu, Z. K., Zhang, G. H., Zhong, D. S., He, J. L., Liu, X., Chen, J. S., et al. (2017). Puerarin ameliorated the behavioral deficits induced by chronic stress in rats. Sci. Rep. 7 (1), 6266. doi: 10.1038/s41598-017-06552-x 
Ramirez, K., and Sheridan, J. F. (2016). Antidepressant imipramine diminishes stress-induced inflammation in the periphery and central nervous system and related anxiety- and depressive- like behaviors. Brain Behav. Immun. 57, $293-$ 303. doi: 10.1016/j.bbi.2016.05.008

Ren, L. X., Luo, Y. F., Li, X., Zuo, D. Y., and Wu, Y. L. (2006). Antidepressant-like effects of sarsasapogenin from Anemarrhena asphodeloides BUNGE (Liliaceae). Biol. Pharm. Bull. 29 (11), 2304-2306. doi: 10.1248/bpb.29.2304

Schmidt, H. D., Shelton, R. C., and Duman, R. S. (2011). Functional biomarkers of depression: diagnosis, treatment, and pathophysiology. Neuropsychopharmacology 36 (12), 2375-2394. doi: 10.1038/npp.2011.151

Simões, L. R., Netto, S., Generoso, J. S., Ceretta, R. A., Valim, R. F., Dominguini, D., et al. (2019). Imipramine treatment reverses depressive- and anxiety-like behaviors, normalize adrenocorticotropic hormone, and reduces interleukin$1 \beta$ in the brain of rats subjected to experimental periapical lesion. Pharmacol. Rep. 71 (1), 24-31. doi: 10.1016/j.pharep.2018.08.003

Tang, J., Xue, W., Xia, B., Ren, L., Tao, W., Chen, C., et al. (2015). Involvement of normalized NMDA receptor and mTOR-related signaling in rapid antidepressant effects of Yueju and ketamine on chronically stressed mice. Sci. Rep. 5, 13573. doi: 10.1038/srep13573

Tantipongpiradet, A., Monthakantirat, O., Vipatpakpaiboon, O., Khampukdee, C., Umehara, K., Noguchi, H., et al. (2019). Effects of Puerarin on the Ovariectomy-Induced Depressive-Like Behavior in ICR Mice and Its Possible Mechanism of Action. Molecules 24 (24), 4569. doi: 10.3390/ molecules 24244569

Ung, C. Y., Li, H., Cao, Z. W., Li, Y. X., and Chen, Y. Z. (2007). Are herb-pairs of traditional Chinese medicine distinguishable from others? Pattern analysis and artificial intelligence classification study of traditionally defined herbal properties. J. Ethnopharmacol. 111, 371-377. doi: 10.1016/j.jep.2006.11.037

Vahdati Hassani, F., Naseri, V., Razavi, B. M., Mehri, S., Abnous, K., and Hosseinzadeh, H. (2014). Antidepressant effects of crocin and its effects on transcript and protein levels of CREB, BDNF, and VGF in rat hippocampus. Daru 22 (1), 16. doi: 10.1186/2008-2231-22-16

Villas Boas, G. R., Boerngen de Lacerda, R., Paes, M. M., Gubert, P., Almeida, W. L. D. C., Rescia, V. C., et al. (2019). Molecular aspects of depression: A review from neurobiology to treatment. Eur. J. Pharmacol. 851, 99-121. doi: 10.1016/ j.ejphar.2019.02.024

Voleti, B., Navarria, A., Liu, R. J., Banasr, M., Li, N., Terwilliger, R., et al. (2013). Scopolamine rapidly increases mammalian target of rapamycin complex 1 signaling, synaptogenesis, and antidepressant behavioral responses. Biol. Psychiatry 74, 742-749. doi: 10.1016/j.biopsych.2013.04.025

Wang, X., Xu, X., Tao, W. Y., Li, Y., Wang, Y. H., and Yang, L. (2012). As systems biology approach to uncovering pharmacological synergy in herbal medicines with applications to cardiovascular disease. Evid. Based. Complement Alternat Med. 2012, 519031. doi: 10.1155/2012/519031

Wang, Z., Gu, J., Wang, X., Xie, K., Luan, Q., Wan, N., et al. (2013). Antidepressant-like activity of resveratrol treatment in the forced swim test and tail suspension test in mice: the HPA axis, BDNF expression and phosphorylation of ERK. Pharmacol. Biochem. Behav. 112, 104-110. doi: 10.1016/j.pbb.2013.10.007

Wang, G. L., He, Z. M., Zhu, H. Y., Gao, Y. G., Zhao, Y., Yang, H., et al. (2017). Involvement of serotonergic, noradrenergic and dopaminergic systems in the antidepressant-like effect of ginsenoside Rb1, a major active ingredient of Panax ginseng C.A. Meyer. J. Ethnopharmacol. 204, 118-124. doi: 10.1016/ j.jep.2017.04.009

Wang, C., Gan, D., Wu, J., Liao, M., Liao, X., and Ai, W. (2018a). Honokiol Exerts Antidepressant Effects in Rats Exposed to Chronic Unpredictable Mild Stress by Regulating Brain Derived Neurotrophic Factor Level and HypothalamusPituitary-Adrenal Axis Activity. Neurochem. Res. 43 (8), 1519-1528. doi: $10.1007 /$ s11064-018-2566-Z

Wang, G. L., Wang, Y. P., Zheng, J. Y., and Zhang, L. X. (2018b). Monoaminergic and aminoacidergic receptors are involved in the antidepressant-like effect of ginsenoside $\mathrm{Rb} 1$ in mouse hippocampus (CA3) and prefrontal cortex. Brain Res. 1699, 44-53. doi: 10.1016/j.brainres.2018.05.035

Wang, G., Lei, C., Tian, Y., Wang, Y., Zhang, L., and Zhang, R. (2019a). Rb1, the Primary Active Ingredient in Panax ginseng C.A. Meyer, Exerts Antidepressant-Like Effects via the BDNF-Trkb-CREB Pathway. Front. Pharmacol. 10, 1034. doi: 10.3389/fphar.2019.01034
Wang, X., Zou, Z., Shen, Q., Huang, Z., Chen, J., Tang, J., et al. (2019b). Involvement of NMDA-AKT-mTOR Signaling in Rapid Antidepressant-Like Activity of Chaihu-jia-Longgu-Muli-tang on Olfactory Bulbectomized Mice. Front. Pharmacol. 9, 1537. doi: 10.3389/fphar.2018.01537

WHO (2017). Depression. https://www.who.int/news-room/fact-sheets/detail/ depression.

Wohleb, E. S., Wu, M., Gerhard, D. M., Taylor, S. R., Picciotto, M. R., Alreja, M., et al. (2016). GABA interneurons mediate the rapid antidepressant-like effects of scopolamine. J. Clin. Invest. 126 (7), 2482-2494. doi: 10.1172/JCI85033

Wu, J., Du, J., Xu, C., Le, J., Xu, Y., Liu, B., et al. (2011). Icariin attenuates social defeat-induced down-regulation of glucocorticoid receptor in mice. Pharmacol. Biochem. Behav. 98 (2), 273-278. doi: 10.1016/ j.pbb.2011.01.008

Xia, B., Zhang, H., Xue, W., Tao, W., Chen, C., Wu, R., et al. (2016). Instant and lasting down-regulation of NR1 expression in the hippocampus is associated temporally with antidepressant activity after acute Yueju Cell. Mol. Neurobiol. 36, 1189-1196. doi: 10.1007/s10571-015-0316-1

Xian, Y. F., Fan, D., Ip, S. P., Mao, Q. Q., and Lin, Z. X. (2017). AntidepressantLike Effect of Isorhynchophylline in Mice. Neurochem. Res. 42 (2), 678-685. doi: 10.1007/s11064-016-2124-5

Xiong, Z., Jiang, B., Wu, P. F., Tian, J., Shi, L. L., Gu, J., et al. (2011). Antidepressant effects of a plant-derived flavonoid baicalein involving extracellular signalregulated kinases cascade. Biol. Pharm. Bull. 34 (2), 253-259. doi: 10.1248/ bpb.34.253

Xu, Y., Ku, B., Tie, L., Yao, H., Jiang, W., Ma, X., et al. (2006). Curcumin reverses the effects of chronic stress on behavior, the HPA axis, BDNF expression and phosphorylation of CREB. Brain Res. 1122 (1), 56-64. doi: 10.1016/ j.brainres.2006.09.009

Xu, D., Wang, C., Zhao, W., Gao, S., and Cui, Z. (2017a). Antidepressant-like effects of ginsenoside Rg5 in mice: Involving of hippocampus BDNF signaling pathway. Neurosci. Lett. 645, 97-105. doi: 10.1016/j.neulet.2017.02.071

Xu, L. Z., Xu, D. F., Han, Y., Liu, L. J., Sun, C. Y., Deng, J. H., et al. (2017b). BDNFGSK-3 $\beta-\beta$-Catenin Pathway in the mPFC Is Involved in Antidepressant-Like Effects of Morinda officinalis Oligosaccharides in Rats. Int. J. Neuropsychopharmacol. 20 (1), 83-93. doi: 10.1093/ijnp/pyw088

Xu, J. N., Chen, L. F., Su, J., Liu, Z. L., Chen, J., Lin, Q. F., et al. (2018). The anxiolytic-like effects of ginsenoside $\mathrm{Rg} 3$ on chronic unpredictable stress in rats. Sci. Rep. 8 (1), 7741. doi: 10.1038/s41598-018-26146-5

Xue, W., Zhou, X., Yi, N., Jiang, L., Tao, W., Wu, R., et al. (2013). Yueju pill rapidly induces antidepressant-like effects and acutely enhances BDNF expression in mouse brain. Evid. Based. Complement Alternat Med. 2013, 184367. doi: $10.1155 / 2013 / 184367$

Yan, H. C., Qu, H. D., Sun, L. R., Li, S. J., Cao, X., Fang, Y. Y., et al. (2010). Fuzi polysaccharide-1 produces antidepressant-like effects in mice. Int. J. Neuropsychopharmacol. 13 (5), 623-633. doi: 10.1017/S1461145709990733

Yan, L., Xu, S. L., Zhu, K. Y., Lam, K. Y., Xin, G., Maiwulanjiang, M., et al. (2015). Optimizing the compatibility of paired-herbs in an ancient Chinese herbal decoction Kai-Xin-San in activating neurofilament expression in cultured PC12 cells. J. Ethnopharmacol. 162, 155-162. doi: 10.1016/j.jep.2014.12.049

Yan, L., Hu, Q., Mak, M. S., Lou, J., Xu, S. L., Bi, C. W., et al. (2016). A Chinese herbal decoction, reformulated from Kai-Xin-San, relieves the depression-like symptoms in stressed rats and induces neurogenesis in cultured neurons. Sci. Rep. 6, 30014. doi: 10.1038/srep30014

Yang, S. J., Yu, H. Y., Kang, D. Y., Ma, Z. Q., Qu, R., Fu, Q., et al. (2014). Antidepressant-like effects of salidroside on olfactory bulbectomy-induced pro-inflammatory cytokine production and hyperactivity of HPA axis in rats. Pharmacol. Biochem. Behav. 124, 451-457. doi: 10.1016/j.pbb.2014.07.015

Ye, J., Cai, S., Cheung, W. M., and Tsang, H. W. H. (2019). An East Meets West Approach to the Understanding of Emotion Dysregulation in Depression: From Perspective to Scientific Evidence. Front. Psychol. 10, 574. doi: 10.3389/ fpsyg.2019.00574

Yi, W. G., and Wetzstein, H. Y. (2011). Anti-tumorigenic activity of five culinary and medicinal herbs grown under greenhouse conditions and their combination effects. J. Sci. Food Agric. 91, 1849-1854. doi: 10.1002/jsfa.4394

You, Z., Yao, Q., Shen, J., Gu, Z., Xu, H., Wu, Z., et al. (2017). Antidepressant-like effects of ginsenoside Rg3 in mice via activation of the hippocampal BDNF signaling cascade. J. Nat. Med. 71 (2), 367-379. doi: 10.1007/s11418-016-1066-1 
Yu, Y., Wang, R., Chen, C., Du, X., Ruan, L., Sun, J., et al. (2013). Antidepressantlike effect of trans-resveratrol in chronic stress model: behavioral and neurochemical evidences. J. Psychiatr. Res. 47 (3), 315-322. doi: 10.1016/ j.jpsychires.2012.10.018

Yu, H., Fan, C., Yang, L., Yu, S., Song, Q., Wang, P., et al. (2018). Ginsenoside Rg1 Prevents Chronic Stress-Induced Depression-Like Behaviors and Neuronal Structural Plasticity in Rats. Cell Physiol. Biochem. 48 (6), 2470-2482. doi: 10.1159/000492684

Zhang, Y. W., and Cheng, Y. C. (2019). Challenge and prospect of Traditional Chinese Medicine in depression treatment. Front. Neurosci. 13, 190. doi: 10.3389/fnins.2019.00190

Zhang, L., Luo, J., Zhang, M., Yao, W., Ma, X., and Yu, S. Y. (2014a). Effects of curcumin on chronic, unpredictable, mild, stress-induced depressive-like behaviour and structural plasticity in the lateral amygdala of rats. Int. J. Neuropsychopharmacol. 17 (5), 793-806. doi: 10.1017/s1461145713001661

Zhang, R., Peng, Z., Wang, H., Xue, F., Chen, Y., Wang, Y., et al. (2014b). Gastrodin ameliorates depressive-like behaviors and up-regulates the expression of BDNF in the hippocampus and hippocampal-derived astrocyte of rats. Neurochem. Res. 39 (1), 172-179. doi: 10.1007/s11064-013-1203-0

Zhang, Q., Guo, F., Fu, Z. W., Zhang, B., Huang, C. G., and Li, Y. (2016). Timosaponin derivative YY-23 acts as a non-competitive NMDA receptor antagonist and exerts a rapid antidepressant-like effect in mice. Acta Pharmacol. Sin. 37 (2), 166-176. doi: 10.1038/aps.2015.111

Zhang, H., Zhou, Z., Chen, Z., Zhong, Z., and Li, Z. (2017). Ginsenoside Rg3 exerts anti-depressive effect on an NMDA-treated cell model and a chronic mild stress animal model. J. Pharmacol. Sci. 134 (1), 45-54. doi: 10.1016/ j.jphs.2017.03.007

Zhao, S., and Iyengar, R. (2012). Systems pharmacology: network analysis to identify multiscale mechanisms of drug action. Annu. Rev. Pharmacol. Toxicol. 52, 505-521. doi: 10.1146/annurev-pharmtox-010611-134520

Zhao, G., Zang, S. Y., Zheng, X. W., Zhang, X. H., and Guo, L. H. (2008). Bakuchiol analogs inhibit monoamine transporters and regulate monoaminergic functions. Biochem. Pharmacol. 75 (9), 1835-1847. doi: 10.1016/j.bcp.2008.01.014

Zhao, X., Yu, C., Wang, C., Zhang, J. F., Zhou, W. H., Cui, W. G., et al. (2014). Chronic resveratrol treatment exerts antihyperalgesic effect and corrects comorbid depressive like behaviors in mice with mononeuropathy: involvement of serotonergic system. Neuropharmacology 85, 131-141. doi: 10.1016/ j.neuropharm.2014.04.021

Zhao, J., Luo, D., Liang, Z., Lao, L., and Rong, J. (2017). Plant Natural Product Puerarin Ameliorates Depressive Behaviors and Chronic Pain in Mice with Spared Nerve Injury (SNI). Mol. Neurobiol. 54 (4), 2801-2812. doi: 10.1007/ s12035-016-9870-x

Zheng, M., Liu, C., Pan, F., Shi, D., Ma, F., Zhang, Y., et al. (2011). Protective effects of flavonoid extract from Apocynum venetum leaves against corticosteroneinduced neurotoxicity in PC12 cells. Cell Mol. Neurobiol. 31 (3), 421-428. doi: 10.1007/s10571-010-9635-4

Zheng, W., Xiang, Y. Q., Ungvari, G. S., Chiu, F. K., Ng, C. H., Wang, Y., et al. (2016). Huperzine A for treatment of cognitive impairment in major depressive disorder: a systematic review of randomized controlled trials. Shanghai Arch. Psychiatry 28 (2), 64-71. doi: 10.11919/j.issn.1002-0829.216003
Zhou, X. J., Liu, M., Yan, J. J., Cao, Y., and Liu, P. (2012). Antidepressant-like effect of the extracted of Kai Xin San, a traditional Chinese herbal prescription, is explained by modulation of the central monoaminergic neurotransmitter system in mouse. J. Ethnopharmacol. 139 (2), 422-428. doi: 10.1016/ j.jep.2011.11.027

Zhou, X., Seto, S. W., Chang, D., Kiat, H., Razmovski-Naumovski, V., Chan, K., et al. (2016). Synergistic effects of chinese herbal medicine: a comprehensive review of methodology and current research. Front. Pharmacol. 7, 201. doi: 10.3389/fphar.2016.00201

Zhou, S. M., Guan, S. Y., Yang, L., Yang, L. K., Wang, L., Nie, H. F., et al. (2017). Cucurbitacin IIa exerts antidepressant-like effects on mice exposed to chronic unpredictable mild stress. Neuroreport 28 (5), 259-267. doi: 10.1097/ WNR.0000000000000747

Zhou, X., Wang, J., Lu, Y., Chen, C., Hu, Y., Liu, P., et al. (2020). Anti-depressive effects of Kai-Xin-San on lipid metabolism in depressed patients and CUMS rats using metabolomic analysis. J. Ethnopharmacol. 252, 112615. doi: 10.1016/ j.jep.2020.112615

Zhu, K. Y., Mao, Q. Q., Ip, S. P., Choi, R. C., Dong, T. T., Lau, D. T., et al. (2012). A standardized chinese herbal decoction, kai-xin-san, restores decreased levels of neurotransmitters and neurotrophic factors in the brain of chronic stressinduced depressive rats. Evid. Based. Complement Alternat Med. 2012, 149256. doi: $10.1155 / 2012 / 149256$

Zhu, X., Gao, R., Liu, Z., Cheng, Z., Qi, Y., Fan, C., et al. (2016a). Ginsenoside Rg1 reverses stress-induced depression-like behaviours and brain-derived neurotrophic factor expression within the prefrontal cortex. Eur. J. Neurosci. 44 (2), 1878-1885. doi: 10.1111/ejn.13255

Zhu, Y., Duan, X., Cheng, X., Cheng, X., Li, X., Zhang, L., et al. (2016b). Kai-XinSan, a standardized traditional Chinese medicine formula, up-regulates the expressions of synaptic proteins on hippocampus of chronic mild stress induced depressive rats and primary cultured rat hippocampal neuron. J. Ethnopharmacol. 193, 423-432. doi: 10.1016/j.jep.2016.09.037

Zhu, Y., Chao, C., Duan, X., Cheng, X., Liu, P., Su, S., et al. (2017). Kai-Xin-San series formulae alleviate depressive-like behaviors on chronic mild stressed mice via regulating neurotrophic factor system on hippocampus. Sci. Rep. 7 (1), 1467. doi: 10.1038/s41598-017-01561-2

Zunszain, P. A., Anacker, C., Cattaneo, A., Carvalho, L. A., and Pariante, C. M. (2011). Glucocorticoids, cytokines and brain abnormalities in depression. Prog. Neuropsychopharmacol. Biol. Psychiatry 35 (3), 722-729. doi: 10.1016/ j.pnpbp.2010.04.011

Conflict of Interest: The authors declare that the research was conducted in the absence of any commercial or financial relationships that could be construed as a potential conflict of interest.

Copyright (c) $2020 \mathrm{Li}$, Huang, Cheng and Zhang. This is an open-access article distributed under the terms of the Creative Commons Attribution License (CC BY). The use, distribution or reproduction in other forums is permitted, provided the original author(s) and the copyright owner(s) are credited and that the original publication in this journal is cited, in accordance with accepted academic practice. No use, distribution or reproduction is permitted which does not comply with these terms. 